Original research article

\title{
The AGTR1 gene A1166C polymorphism as a risk factor and outcome predictor of primary intracerebral and aneurysmal subarachnoid hemorrhages
}

Mateusz G. Adamski ${ }^{a, b, *}$, Aleksandra Golenia ${ }^{a}$, Wojciech Turaj ${ }^{a}$, Alison E. Baird ${ }^{b}$, Marek Moskala ${ }^{c}$, Tomasz Dziedzic ${ }^{a}$, Andrzej Szczudlik ${ }^{a}$, Agnieszka Slowik ${ }^{a}$, Joanna Pera ${ }^{a}$

${ }^{a}$ Department of Neurology, Jagiellonian University Medical College, Krakow, Poland

${ }^{\mathrm{b}}$ Department of Neurology, SUNY Downstate Medical Center, Brooklyn, USA

${ }^{\mathrm{c}}$ Department of Neurosurgery and Neurotraumatology, Jagiellonian University Medical College, Krakow, Poland

\section{A R T I C L E I N F O}

Article history:

Received 8 April 2014

Accepted 14 July 2014

Available online 29 July 2014

\section{Keywords:}

AGRT1

Intracerebral hemorrhage

Aneurysmal subarachnoid

hemorrhage

Outcome

Stroke

\begin{abstract}
A B S T R A C T
Associations between the angiotensin II type 1 receptor (AGTR1) gene A1166C polymorphism and hypertension, aortic abdominal aneurysms (as a risk factor) as well as cardiovascular disorders (as a risk factor and an outcome predictor) have been demonstrated. We aimed to investigate the role of this polymorphism as risk factors and outcome predictors in primary intracerebral hemorrhage (PICH) and aneurysmal subarachnoid hemorrhage (aSAH).

We have prospectively recruited 1078 Polish participants to the study: 261 PICH patients, 392 aSAH patients, and 425 unrelated control subjects. The A1166C AGTR1 gene polymorphism was studied using the tetra-primer ARMS-PCR method. Allele and genotype frequencies were compared with other ethnically different populations.

The A1166C polymorphism was not associated with the risk of PICH or aSAH. Among the aSAH patients the AA genotype was associated with a good outcome, defined by a Glasgow Outcome Scale of 4 or $5(p<0.02)$. The distribution of A1166C genotypes in our cohort did not differ from other white or other populations of European descent.

In conclusion, we found an association between the A1166C AGTR1 polymorphism and outcome of aSAH patients, but not with the risk of PICH or aSAH.

(C) 2014 Polish Neurological Society. Published by Elsevier Urban \& Partner Sp. z o.o. All rights reserved.
\end{abstract}

\footnotetext{
* Corresponding author at: Department of Neurology, Jagiellonian University Medical College, ul. Botaniczna 3, 31-503 Krakow, Poland. Tel.: +48 12 4248600; fax: +48 124248626 .

E-mail addresses: adamskimateusz@yahoo.com, mateusz.adamski@downstate.edu (M.G. Adamski). http://dx.doi.org/10.1016/j.pjnns.2014.07.007 0028-3843/ (C) 2014 Polish Neurological Society. Published by Elsevier Urban \& Partner Sp. z o.o. All rights reserved.
} 


\section{Introduction}

Stroke is one of the leading causes of death and disability. Approximately $87 \%$ of all strokes are ischemic, $10 \%$ are intracerebral hemorrhagic strokes (ICH) and the remaining $3 \%$ are subarachnoid hemorrhages (SAH) [1]. The latter are in about $85 \%$ of aneurysmal origin (aSAH) [2]. The 30-day mortality rate for aSAH is $32-45 \%[3,4]$ and for $\mathrm{PICH}$ is $35-$ $52 \%[5,6]$, with an overall one year mortality of $20-52 \%[1,6]$. Thus, both hemorrhagic subtypes of stroke have more than twice higher mortality rate than ischemic stroke (IS) and share number of risk factors including hypertension (HT), smoking, and alcohol abuse.

Angiotensin II receptor type 1 (AGTR1), encoded by the AGTR1 gene is the first of two angiotensin II (AII) receptors. AII is a crucial neurohormone in the renin-angiotensin-aldosterone system and plays an important role in the pathophysiology of HT. The CC genotype of the A1166C single nucleotide polymorphism (SNP) (ID: rs5186) of the AGTR1 gene has been shown to increase the response to AII, resulting in an increased risk of cardiovascular disease [7].

C allele or CC genotype of the A1166C polymorphism were found to be associated with an increased risk of hypertension (C allele) [8], aortic stiffness (CC genotype) [9], left ventricular hypertrophy (C allele) [10], myocardial infarction (CC genotype) [11], and abdominal aortic aneurysm (C allele) [12]. Recently, this polymorphism has also been recognized as an outcome predictor in two groups of patients with cardiovascular diseases. In patients after percutaneous coronary intervention it was associated with long term clinical outcome defined as death, repeat revascularization and myocardial infarction [13]. In heart failure and reduced systolic function it was associated with poor prognostic markers and increased mortality [14].

Results of a recent meta-analysis indicate that the A1166C polymorphism is not associated with susceptibility to IS [15]. These findings were adjusted to the variability of allele distribution across ethnically different populations. To the best of our knowledge the significance of this polymorphism has only been studied in two, small groups of hemorrhagic stroke patients ( $<50$ subjects), where hemorrhagic stroke etiology was not assessed [16,17].

The aim of this study was to evaluate the role of A1166C AGTR1 gene polymorphism as risk factors and outcome predictors in two types of hemorrhagic stroke i.e., PICH and aSAH among Polish patients. An additional analysis of allele distribution across various ethnic groups was also carried out.

\section{Materials and methods}

This study was approved by the Ethical Committee of the Jagiellonian University.

\subsection{Study subjects}

After full and signed informed consent given by study subjects or their family member, 1078 participants were enrolled to the study. $261 \mathrm{PICH}$ and $392 \mathrm{aSAH}$ patients were prospectively recruited from subjects consecutively admitted to the Department of Neurology or Neurosurgery and Neurotraumatology, University Hospital Krakow, Poland between 2002 and 2010. PICH was diagnosed based on noncontrast cranial computed tomography (CT). Patients with secondary intracerebral hemorrhage (SICH) due to vascular malformations, head trauma, brain tumor, hematologic abnormalities or hemorrhagic transformation of IS were excluded. SAH was diagnosed by cranial CT and/or lumbar puncture. The diagnosis of a saccular aneurysm was established by digital subtraction angiography or angio-CT. Only patients with non-traumatic aSAH were included into the study. Details on aSAH and PICH patients recruitment are provided in a Supplementary Figure 1. 425 unrelated control subjects free from cerebrovascular and neurological diseases were recruited from the relatives of hospital staff, patients of the University Hospital hospitalized for any reason other than neurological diseases and spouses of the patients of the Department of Neurology. Demographic and risk factor profiles were collected using a questionnaire described previously $[18,19]$. In particular, we have collected information on age, gender, race, HT, hypercholesterolemia, obesity, diabetes mellitus and current smoking. Glasgow Outcome Scale (GOS) was assessed for PICH and aSAH patients at discharge. Good outcome was defined as a GOS of 4 or 5 , whereas poor outcome was defined as a GOS of 1-3.

Supplementary Figure 1 related to this article can be found, in the online version, at doi:10.1016/j.pjnns.2014.07.007.

\subsection{Genotyping}

Uncuffed venous blood samples for extraction of DNA were drawn from each subject within a week from enrollment. Leukocyte DNA was extracted using a commercially available kit (High Pure PCR template Preparation Kit; Boehringer Mannheim). The A1166C AGTR1 gene polymorphism was studied using the tetra-primer ARMS-PCR method, adapted from Ye et al. [20].

\subsection{Statistical analysis}

Study power for A1166C polymorphism both for PICH and aSAH groups was calculated. Rare homozygote and heterozygote (CC, AC) were combined and tested vs common homozygote (AA). aSAH power analysis revealed that a study of this size has $80 \%$ power at a type I error probability of alpha $=0.05$ to detect a $10 \%$ difference between tested populations. PICH power analysis revealed that a study of this size has $80 \%$ power at a type I error probability alpha $=0.05$ to detect a $13 \%$ difference between tested populations.

Differences between patients and controls for continuous data were tested with Student's t-test. Categorical variables were tested with $\chi^{2}$ test or Fisher exact test (where applicable). The deviation from Hardy-Weinberg equilibrium for tested polymorphism was examined by $\chi^{2}$ test. To measure the associations between studied allele or genotypes and selected variables odds ratios (OR) and 95\% confidence intervals (95\% CI) were calculated. Logistic regression analysis was used to test hypotheses about relations between categorical binominal variables and one or more categorical or continuous predictor variables. A value of $p<0.05$ was considered significant. 
Table 1 - Characteristics of the study subjects.

\begin{tabular}{|c|c|c|c|c|c|}
\hline & $\begin{array}{l}\text { Control subjects } \\
\text { (CS) }(n=425)\end{array}$ & $\begin{array}{l}\text { aSAH patients } \\
(n=392)\end{array}$ & $\begin{array}{l}\text { PICH patients } \\
\quad(n=261)\end{array}$ & $\begin{array}{c}p \\
\text { aSAH vs CS }\end{array}$ & $\begin{array}{c}p \\
\text { PICH vs CS }\end{array}$ \\
\hline Age, years; mean $( \pm S D)$ & $64.15(12.05)$ & $51.23(12.63)$ & $66.12(13.54)$ & $<0.001$ & ns \\
\hline Gender, male & $60.5 \%$ & $57.5 \%$ & $50.6 \%$ & ns & $<0.05$ \\
\hline HT & $48.8 \%$ & $61 \%$ & $79 \%$ & $<0.001$ & $<0.001$ \\
\hline Hypercholesterolemia & $35.6 \%$ & $21 \%$ & $38 \%$ & $<0.001$ & ns \\
\hline Obesity & $20.9 \%$ & $13.4 \%$ & $24.2 \%$ & $<0.05$ & ns \\
\hline Diabetes mellitus & $12 \%$ & $7.7 \%$ & $17 \%$ & ns & ns \\
\hline Current smoking & $19.9 \%$ & $47.2 \%$ & $28.9 \%$ & $<0.001$ & $<0.05$ \\
\hline
\end{tabular}

aSAH, aneurysmal subarachnoid hemorrhage; PICH, primary intracerebral hemorrhage; SD, standard deviation; HT, hypertension; ns, non significant; $p$ values were obtained with $t$-test (age) and Fisher exact test (rest of variables).

\section{Results}

The demographic data and risk factor profiles of patients and controls are presented in Table 1 . The control group was older than the aSAH group but not when compared to the PICH group. In comparison to the control group, the percentage of females was higher in the PICH group, but not different to the aSAH group.

The allele distribution of the investigated polymorphism did not deviate from Hardy-Weinberg equilibrium for the controls, PICH or aSAH patients. The frequencies of the studied genotypes and alleles were similar in all of the stroke patients and control subjects (Table 2).

In logistic regression analysis, the recessive genotype-AA vs AC and CC - was the independent variable and age, gender, HT, and GOS outcome were the dependent variables. Results are presented in Table 3. In the aSAH group AA carriers had better outcome $(\mathrm{OR}=1.62 ; p<0.02)$ and were more likely to be older $(\mathrm{OR}=1.02 ; p<0.03)$. After adjustment for $\mathrm{HT}$ the results remained significant for GOS of $4-5(\mathrm{OR}=1.89$; $95 \% \mathrm{CI}$ : $1.01-$ 3.54, $p=0.04)$. A validation model where logistic regression analysis was adjusted to (GOS, age, gender, smoking and hypercholesterolemia) confirmed our findings, AA carriers had better outcome (OR = 1.44; 95\% CI: 1.08-1.91, $p=0.01)$ and were more likely to be younger (OR $=1.07 ; 95 \% \mathrm{CI}: 1.03-1.1, p<0.001$ ).

The results of comparisons between genotype and allele distributions in our control group and groups of different ethnicity are summarized in Fig. 1. Our Polish cohort does not differ from New Zealand, United Kingdom, Western Australian and white American cohorts [12,18]. In contrast, African American, Chinese, and Japanese cohorts, which were similar to each other, significantly differ in allele and genotype distribution when compared with the studied Polish population $(p<0.0001)$ [21-23].

\section{Discussion}

There are three major findings in the present study of the A1166C AGTR1 gene polymorphism in hemorrhagic strokes: (1) the A1166C polymorphism is not associated with the risk of PICH or aSAH, (2) AA genotype is associated with better outcome in aSAH patients, and (3) A1166C distribution varies across populations of different ethnicity.

Analyses performed within studied stroke groups revealed interesting results for aSAH patients. Contrary to CC and AC genotypes, AA homozygotes in the aSAH group were more likely to have good outcomes (GOS 4-5). Although A1166C is not directly associated with stroke risk it correlates with stroke outcome in the aSAH group. Its effect on outcome was also shown in patients after percutaneous coronary interventions and in patients with heart failure and reduced systolic function patient [13,14]. Based on mice models several authors have shown that interaction of AII with activated $\mathrm{T}$ leukocytes contributes to T-cell cytokine production and tissue invasion [24-26]. Since A1166C is a functional polymorphism, with CC genotype being related both to increased response to AII and to worse clinical outcomes, we speculate that $C$ allele may be related to the delayed vascular damage, and in effect, aSAH outcome.

According to our knowledge this is the first paper to assess the role of the A1166C AGTR1 gene polymorphism in two hemorrhagic stroke etiologies: aSAH and PICH. Although A1166C is associated with hypertension, a major risk factor for both aSAH (OR = 2.6) [27] and PICH (OR = 5.7) [28], it was not associated with the risk of the stroke etiologies studied. Our results and

Table 2 - The AGTR1 gene A1166C polymorphism: genotypes and allele frequencies in control subjects, aSAH and PICH patients.

\begin{tabular}{lcccccc} 
& $\begin{array}{c}\text { Control subjects } \\
(\mathrm{CS})(n=425)\end{array}$ & $\begin{array}{c}\text { aSAH patients } \\
(n=392)\end{array}$ & $\begin{array}{c}\text { PICH patients } \\
(n=261)\end{array}$ & $\begin{array}{c}p \\
\text { aSAH vs CS }\end{array}$ & $\begin{array}{c}p \\
\text { PICH vs CS }\end{array}$ & $\begin{array}{c}p \\
\text { aSAH vs PICH }\end{array}$ \\
\hline AA & $51.6 \%$ & $52.6 \%$ & $55.9 \%$ & $\mathrm{~ns}$ & $\mathrm{~ns}$ & $\mathrm{~ns}$ \\
$\mathrm{AC}$ & $35.8 \%$ & $41.6 \%$ & $39.1 \%$ & $\mathrm{~ns}$ & $\mathrm{~ns}$ & $\mathrm{~ns}$ \\
$\mathrm{CC}$ & $5.9 \%$ & $5.9 \%$ & $5 \%$ & $\mathrm{~ns}$ & $\mathrm{~ns}$ & $\mathrm{~ns}$ \\
$\mathrm{~A}$ & $69.6 \%$ & $73.3 \%$ & $75.5 \%$ & $\mathrm{~ns}$ & $\mathrm{~ns}$ & $\mathrm{~ns}$ \\
\hline
\end{tabular}

aSAH, aneurysmal subarachnoid hemorrhage; PICH, primary intracerebral hemorrhage; ns, non significant; $p$ values were obtained with $\chi^{2}$ test. 
Table 3 - Logistic regression analysis.

\begin{tabular}{|c|c|c|c|}
\hline$A A$ vs $A C$ and $C C$ & PICH, OR (95\% CI); $p$ & aSAH, OR (95\% CI); $p$ & $\begin{array}{l}\text { Control subjects, } \\
\text { OR (95\% CI); } p\end{array}$ \\
\hline GOS 4-5 & 0.99 (0.57-1.73); ns & 1.62 (1.05-2.50); 0.02 & - \\
\hline HT & 1.28 (0.63-2.59); ns & $0.86(0.56-1.31) ; \mathrm{ns}$ & $0.77(0.52-1.13) ; \mathrm{ns}$ \\
\hline Age & 1.00 (0.98-1.02); ns & 1.02 (1.00-1.04); 0.03 & 1.00 (0.98-1.02); ns \\
\hline Male gender & 1.71 (0.96-3.03); 0.06 & 0.79 (0.52-1.20); ns & 1.04 (0.70-1.52); ns \\
\hline
\end{tabular}

\section{AGTR1 genotype frequencies}

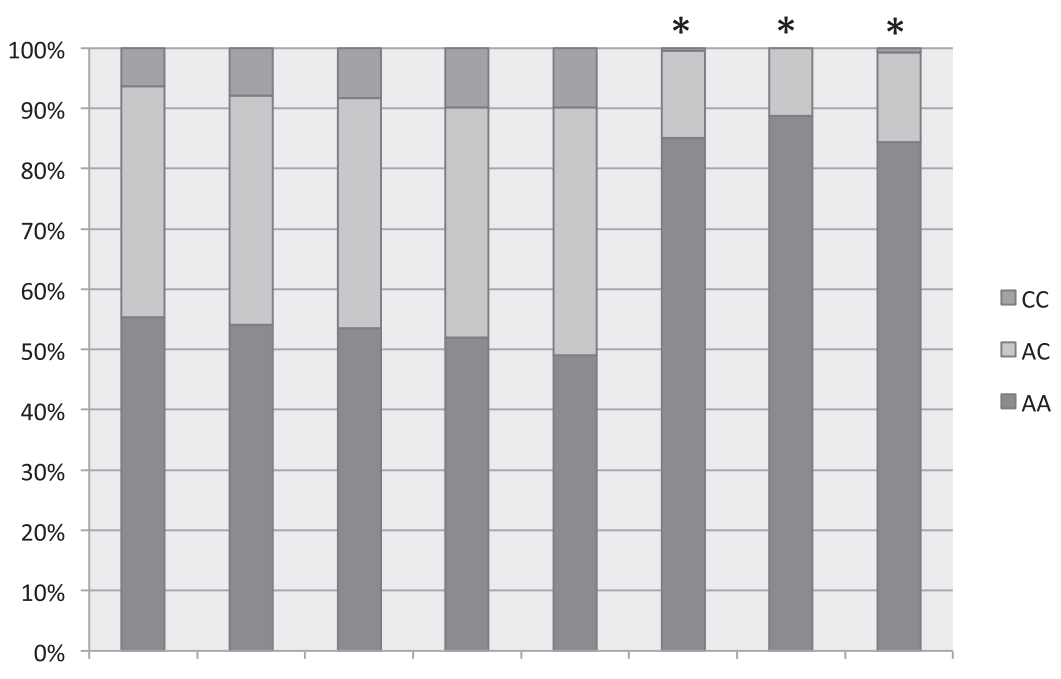

\section{AGTR1 allele frequencies}

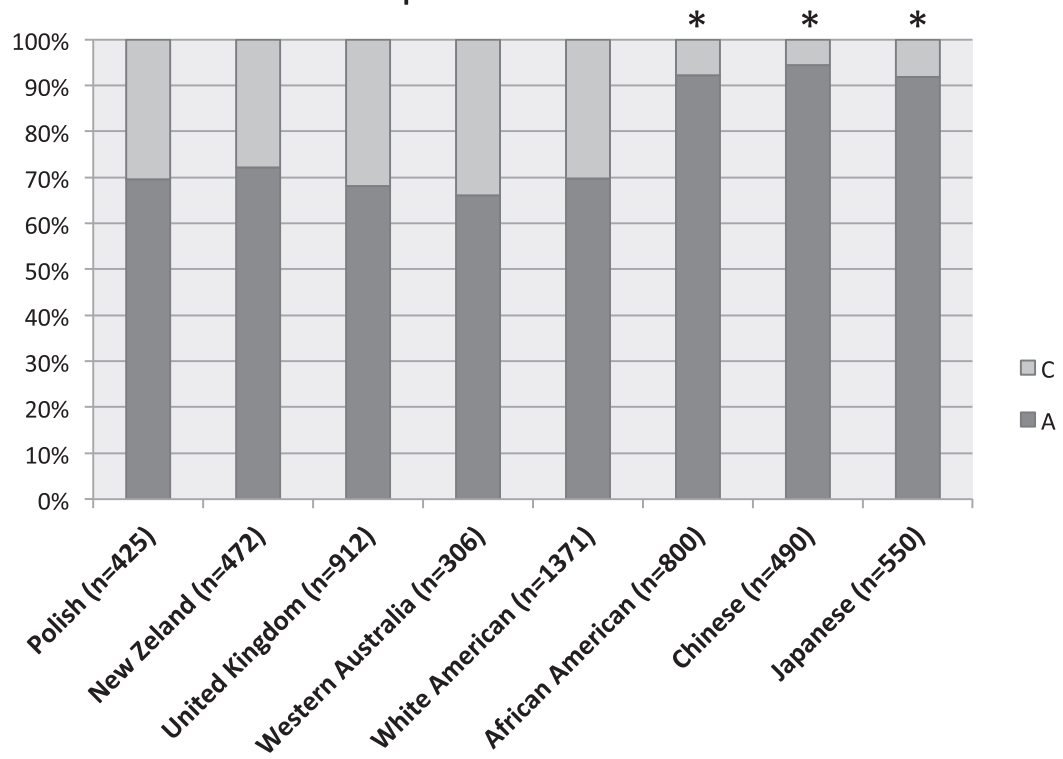

Fig. 1 - Comparison of AGRT1 gene A1166C genotypes and allele frequencies across different populations of different ethnicity. Frequencies of genotypes and alleles observed in control group in our study (Polish) were compared to frequencies in control groups observed in studies by Jones et al. [12] (New Zeland, United Kingdom, Western Australian), Hindorff et al. [18] (White Americans, African American), Thomas et al. [19] (Chinese), Akasaka et al. [20] (Japanese). *Significant difference $(p<0.05)$ based on $\chi^{2}$ test. 
those from previous studies on IS and its subtypes suggest that A1166C polymorphism does not affect the risk of stroke $[27,28]$.

We have compared allele and genotype distributions between the current Polish control group and a number of control groups of different ethnicity and race (Fig. 1). Our control group was not different to a control group from the United Kingdom, white Americans, or Western Australian and New Zealand groups. In contrast, Chinese, Japanese and African American groups showed significantly different allele and genotype distributions from our control group. According to the NCBI SNP database [29], the frequency of the C allele in Asian and African American populations is below 10\%, whereas in White populations it is above $25 \%$. Our analysis and NCBI data on SNP distribution suggest that our findings may be applicable to white or populations of European descent but that African and Asian group should be analyzed separately.

There are several potential limitations of our study. First, control subjects were not perfectly matched to the hemorrhagic patients. Due to a significant difference between the mean age of the aSAH and PICH groups we have chosen to recruit older subjects to the control group in order to match to the PICH group. The proportion of males in the control group was $10 \%$ higher than in the ICH group. However, in logistic regression analysis neither age nor gender was associated with genotype distribution in the control group, and therefore we do not expect that these differences could affect our results. The difference in the average allele and genotype distribution between the control group and the PICH or aSAH groups ranged from 1 to $6 \%$. In order to confirm the lack of difference in allele and genotype distribution with these numbers, at a power of $80 \%(\beta=0.8)$ and $\alpha=0.05$, the study groups would need to be increased to more than 39,000 participants. Finally, due to relatively small sample size of aSAH patients association between the polymorphism and good outcome may be false positive. Therefore replication in an independent cohort is needed to confirm our finding.

In conclusion we found an association between the AA genotype of the A1166C AGTR1 gene polymorphism and good outcome among aSAH patients. Our results suggest that there is no associations of this polymorphism with the risk of either $\mathrm{PICH}$ or aSAH stroke in a Polish population.

\section{Conflict of interest}

None declared.

\section{Acknowledgment and financial support}

This research was supported by: Leading National Research Center (KNOW), Jagiellonian University Medical College, Krakow, Poland (JP); National Institutes of Health grants NIBIB R01 EB010087 and NIMH R21 MH097639 (AEB).

\section{Ethics}

The work described in this article has been carried out in accordance with The Code of Ethics of the World Medical
Association (Declaration of Helsinki) for experiments involving humans; Uniform Requirements for manuscripts submitted to Biomedical journals.

\section{R E F E R E N C E S}

[1] Go AS, Mozaffarian D, Roger VL, Benjamin EJ, Berry JD, Borden WB, et al. Heart disease and stroke statistics - 2013 update: a report from the American Heart Association. Circulation 2013;127:e6-245.

[2] Al-Shahi R, White PM, Davenport RJ, Lindsay KW. Subarachnoid haemorrhage. BMJ 2006;333:235-40.

[3] Connolly ES, Rabinstein AA, Carhuapoma JR, Derdeyn CP, Dion J, Higashida RT, et al. Guidelines for the management of aneurysmal subarachnoid hemorrhage: a guideline for healthcare professionals from the American Heart Association/American Stroke Association. Stroke 2012;43:1711-37.

[4] Adamski MG, Li Y, Wagner E, Yu H, Seales-Bailey C, Soper SA, et al. Next-generation qPCR for the high-throughput measurement of gene expression in multiple leukocyte subsets. J Biomol Screen 2013;18:1008-17.

[5] Rordorf G, McDonald C. Spontaneous intracerebral hemorrhage: prognosis and treatment. In: Basow D, editor. UpToDate. Waltham, MA: UpToDate; 2013.

[6] Christensen MC, Munro V. Ischemic stroke and intracerebral hemorrhage: the latest evidence on mortality, readmissions and hospital costs from Scotland. Neuroepidemiology 2008;30:239-46.

[7] Van Geel PP, Pinto YM, Voors AA, Buikema H, Oosterga M, Crijns HJ, et al. Angiotensin II type 1 receptor A1166C gene polymorphism is associated with an increased response to angiotensin II in human arteries. Hypertension 2000;35: 717-21.

[8] Bonnardeaux A, Davies E, Jeunemaitre X, Féry I, Charru A, Clauser E, et al. Angiotensin II type 1 receptor gene polymorphisms in human essential hypertension. Hypertension 1994;24:63-9.

[9] Benetos A, Gautier S, Ricard S, Topouchian J, Asmar R, Poirier $\mathrm{O}$, et al. Influence of angiotensin-converting enzyme and angiotensin II type 1 receptor gene polymorphisms on aortic stiffness in normotensive and hypertensive patients. Circulation 1996;94:698-703.

[10] Osterop AP, Kofflard MJ, Sandkuijl LA, ten Cate FJ, Krams R, Schalekamp MA, et al. AT1 receptor A/C1166 polymorphism contributes to cardiac hypertrophy in subjects with hypertrophic cardiomyopathy. Hypertension 1998;32: 825-30.

[11] Tiret L, Bonnardeaux A, Poirier O, Ricard S, Marques-Vidal P, Evans A, et al. Synergistic effects of angiotensin-converting enzyme and angiotensin-II type 1 receptor gene polymorphisms on risk of myocardial infarction. Lancet 1994;344:910-3.

[12] Jones GT, Thompson AR, van Bockxmeer FM, Hafez H, Cooper JA, Golledge J, et al. Angiotensin II type 1 receptor $1166 \mathrm{C}$ polymorphism is associated with abdominal aortic aneurysm in three independent cohorts. Arterioscler Thromb Vasc Biol 2008;28:764-70.

[13] Bernat R, Szavits-Nossan J, Trbović A, Kapov-Svilicić K, Sesto I, Sipić T. Relationship of genetic markers for atherosclerosis and long-term outcome after percutaneous coronary intervention with stenting. Coll Antropol 2012;36:1385-90.

[14] Amir O, Amir RE, Paz H, Attias E, Sagiv M, Lewis BS. Relation between AT1R gene polymorphism and long-term outcome in patients with heart failure. Cardiology 2009;112:151-7. 
[15] Zhang H, Sun M, Sun T, Zhang C, Meng X, Zhang Y, et al. Association between angiotensin II type 1 receptor gene polymorphisms and ischemic stroke: a meta-analysis. Cerebrovasc Dis 2011;32:431-8.

[16] Hulyam K, Aysegul B, Veysi GH, Demet O, Irfan D, Ertugrul $\mathrm{C}$, et al. Frequency of angiotensin II type 1 receptor gene polymorphism in Turkish acute stroke patients. J Cell Mol Med 2013;17:475-81.

[17] Möllsten A, Stegmayr B, Wiklund P-G. Genetic polymorphisms in the renin-angiotensin system confer increased risk of stroke independently of blood pressure: a nested case-control study. J Hypertens 2008;26:1367-72.

[18] Adamski MG, Borratynska A, Krupa M, Wloch-Kopec D, Turaj W, Wolkow P, et al. A1/A2 polymorphism of GpIIIa gene and a risk of aneurysmal subarachnoid haemorrhage. Biochem Biophys Res Commun 2009;383:228-30.

[19] Slowik A, Turaj W, Dziedzic T, Haefele A, Pera J, Malecki MT, et al. DD genotype of ACE gene is a risk factor for intracerebral hemorrhage. Neurology 2004;63:359-61.

[20] Ye S, Dhillon S, Ke X, Collins AR, Day IN. An efficient procedure for genotyping single nucleotide polymorphisms. Nucleic Acids Res 2001;29:E88-98.

[21] Hindorff LA, Heckbert SR, Tracy R, Tang Z, Psaty BM, Edwards KL, et al. Angiotensin II type 1 receptor polymorphisms in the cardiovascular health study: relation to blood pressure, ethnicity, and cardiovascular events. Am J Hypertens 2002;15:1050-6.

[22] Thomas GN, Lin JW, Lam WWM, Tomlinson B, Yeung V, Chan JCN, et al. Middle cerebral artery stenosis in type II diabetic Chinese patients is associated with conventional risk factors but not with polymorphisms of the reninangiotensin system genes. Cerebrovasc Dis 2003;16:217-23.

[23] Akasaka H, Katsuya T, Saitoh S, Sugimoto K, Fu Y, Takagi S, et al. Effects of angiotensin II type 1 receptor gene polymorphisms on insulin resistance in a Japanese general population: the Tanno-Sobetsu study. Hypertens Res 2006;29:961-7.

[24] Guzik TJ, Hoch NE, Brown KA, McCann LA, Rahman A, Dikalov $\mathrm{S}$, et al. Role of the $\mathrm{T}$ cell in the genesis of angiotensin II induced hypertension and vascular dysfunction. J Exp Med 2007;204:2449-60.

[25] Silva-Filho JL, Souza MC, Henriques M, das G, Morrot A, Savino W, et al. AT1 receptor-mediated angiotensin II activation and chemotaxis of T lymphocytes. Mol Immunol 2011;48:1835-43.

[26] Maeda A, Okazaki T, Inoue M, Kitazono T, Yamasaki M, Lemonnier FA, et al. Immunosuppressive effect of angiotensin receptor blocker on stimulation of mice CTLs by angiotensin II. Int Immunopharmacol 2009;9:1183-8.

[27] Feigin VL, Rinkel GJE, Lawes CMM, Algra A, Bennett DA, van Gijn J, et al. Risk factors for subarachnoid hemorrhage: an updated systematic review of epidemiological studies. Stroke 2005;36:2773-80.

[28] Feldmann E, Broderick JP, Kernan WN, Viscoli CM, Brass LM, Brott $\mathrm{T}$, et al. Major risk factors for intracerebral hemorrhage in the young are modifiable. Stroke 2005;36:1881-5.

[29] Sherry ST, Ward MH, Kholodov M, Baker J, Phan L, Smigielski EM, et al. dbSNP: the NCBI database of genetic variation. Nucleic Acids Res 2001;29:308-11. 